Issued by Sandia National Laboratories, operated for the United States Department of Energy by Sandia Corporation.

NOTICE: This report was prepared as an account of work sponsored by an agency of the United States Government. Neither the United States Government, nor any agency thereof, nor any of their employees, nor any of their contractors, subcontractors, or their employees, make any warranty, express or implied, or assume any legal liability or responsibility for the accuracy, completeness, or usefulness of any information, apparatus, product, or process disclosed, or represent that its use would not infringe privately owned rights. Reference herein to any specific commercial product, process, or service by trade name, trademark, manufacturer, or otherwise, does not necessarily constitute or imply its endorsement, recommendation, or favoring by the United States Government, any agency thereof, or any of their contractors or subcontractors. The views and opinions expressed herein do not necessarily state or reflect those of the United States Government, any agency thereof, or any of their contractors.

Printed in the United States of America. This report has been reproduced directly from the best available copy.

Available to DOE and DOE contractors from

Office of Scientific and Technical Information

P.O. Box 62

Oak Ridge, TN 37831

Prices available from (703) 605-6000

Web site: http://www.ntis.gov/ordering.htm

Available to the public from

National Technical Information Service

U.S. Department of Commerce

5285 Port Royal Rd

Springfield, VA 22161

NTIS price codes

Printed copy: A03

Microfiche copy: A01

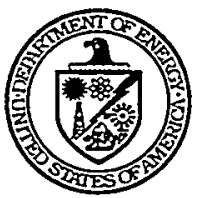




\section{DISCLAIMER}

Portions of this document may be illegible in electronic image products. Images are produced from the best available original document. 
SAND2000-8209

Unlimited Distribution

Printed December 1999

\title{
CHAMBER LEAKAGE EFFECTS ON MEASURED GAS CONCENTRATIONS DURING CONTAINED DEMILITARIZATION TESTS AT NTS X-TUNNEL
}

\author{
Christopher R. Shaddix \\ Combustion Research Facility \\ and \\ Joel Lipkin \\ Technology Applications Department \\ Sandia National Laboratories \\ Livermore, CA 94550
}

\begin{abstract}
A series of contained explosive detonation and propellant burn experiments was conducted during 1996 and 1997 using a specially constructed, large, underground chamber located in the X-tunnel complex at Area 25 of the Nevada Test Site (NTS). The detonation tests employed 155-mm HE M107 projectiles and the propellant burn tests used NIKE M88 and Improved Hawk rocket motors. These experiments were performed as part of the Joint Demil Technology (JDT) Program between the Departments of Defense and Energy. An important goal of these experiments was characterization of the gaseous and particulate emissions associated with using typical disposal methods for excess munitions. Interpretation of the gas emissions from these tests requires extrapolation of measured, time-delayed gas species concentrations back to the time at the end of burn. This process is confounded by significant and sometimes non-monotonic variations in the measured species profiles with time. When analyzing the results for these tests, researchers at Lawrence Livermore National Laboratory (LLNL) attributed the measured temporal variations to the effects of carbon dioxide absorption onto the test chamber walls. However, trends in the data for the largest rocket motor demil test, Thunderbird, suggest that air dilution of the chamber gases could also be important. In the present work, an analytic framework for evaluating the relative influence of $\mathrm{CO}_{2}$ absorption and air dilution is developed and applied to the three rocket motor burn tests conducted in 1997. During the first two tests, Sunspot and Thunderbird, significant air dilution of the sampled chamber gases is evident at late sampling times ( $>100 \mathrm{~min})$, when the chamber pressure is at or slightly less than the ambient pressure. Evidence of some contribution from $\mathrm{CO}_{2}$ absorption throughout the sampling period is also apparent for these two experiments. During the final test, Dazzler, no significant leakage occurred from the chamber, preventing air dilution effects, and almost no $\mathrm{CO}_{2}$ absorption is evident, either. Knowledge of the $\mathrm{CO}_{2}$ absorption rate allows reasonable estimation of the chamber composition at the end of burn. The end-of-burn concentrations deduced from the current analysis show good consistency with the measured gas species temporal trends and give better agreement with the LLNL-calculated "expected" concentrations than those that were previously generated by LLNL personnel using simplified fits of the temporal species profiles.
\end{abstract}




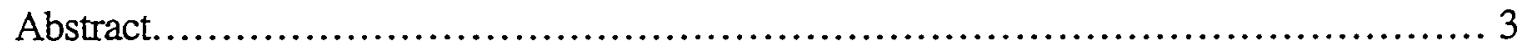

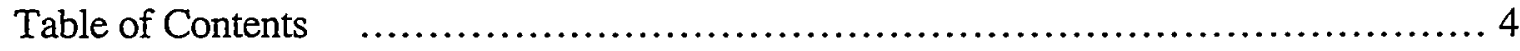

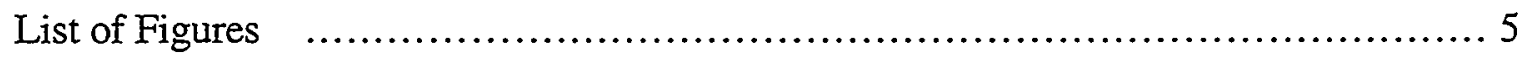

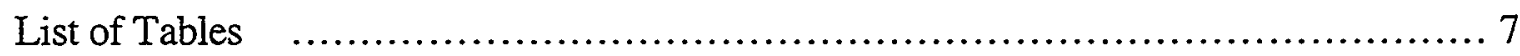

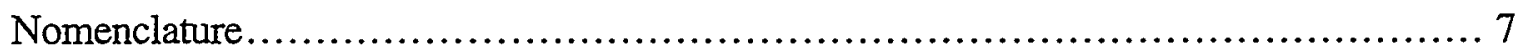

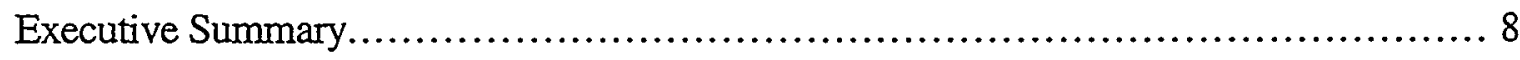

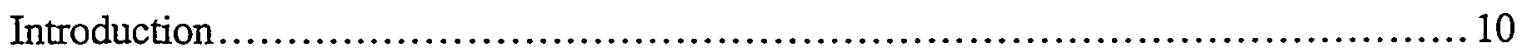

Gas Sampling Data........................................................... 10

Test Chamber Leakage ........................................................ 11

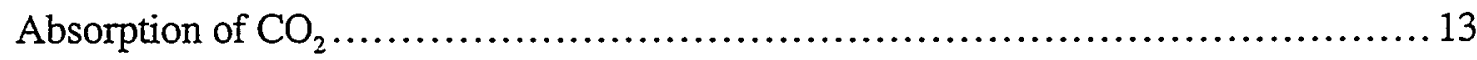

Gas Analysis Implications .................................................. 13

Gas Concentration Analysis ..................................................... 14

Results and Implications ..................................................... 17

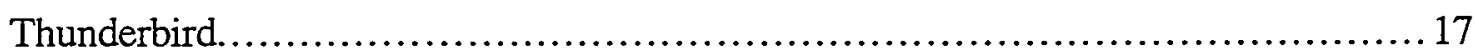

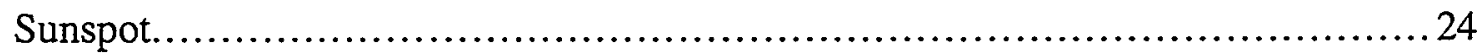

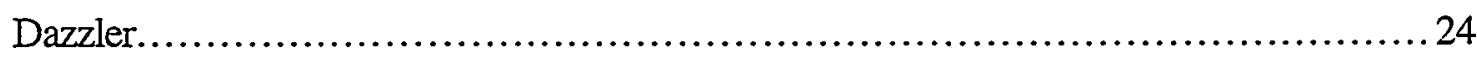

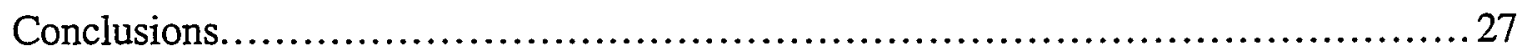

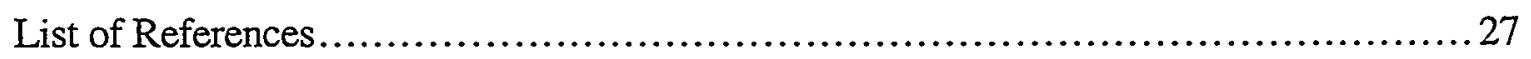


Figure 1. Chamber pressure histories during the rocket motor burn tests. Preshot chamber pressures are denoted by the dashed lines and the final, thermal equilibrium pressures (ignoring any leakage from the chamber or reactions with the walls) are also indicated.

Figure 2. Measured and calculated temporal evolution of krypton in the test chamber during Thunderbird. The calculations are initiated with the measured species concentrations at $t=80$ minutes. Enror bars indicate measurement uncertainty.

Figure 3. Air dilution factors and $\mathrm{CO}_{2}$ absorption factors from the combined effects calculation during the latter sample times of Thunderbird. The calculations are initiated with the measured species concentrations at $\mathrm{t}=80$ minutes.

Figure 4. Measured and calculated temporal evolution of nitrogen in the test chamber during Thunderbird. The calculations are initiated with the measured species concentrations at $t=80$ minutes. The starburst indicates the calculated end-of-burn value.

Figure 5. Measured and calculated temporal evolution of nitrogen in the test chamber during Thunderbird. The calculations are initiated with the measured species concentrations at $t=14$ minutes. The starburst indicates the calculated end-of-burn value

Figure 6. Measured and calculated temporal evolution of oxygen in the test chamber during Thunderbird. The calculations are initiated with the measured species concentrations at $t=80$ minutes. The starburst indicates the calculated end-of-burn value

Figure 7. Measured and calculated temporal evolution of oxygen in the test chamber during Thunderbird. The calculations are initiated with the measured species concentrations at $t=14$ minutes. The starburst indicates the calculated end-of-burn value

Figure 8. Measured and calculated temporal evolution of nitrogen in the test chamber during Sunspot. The calculations are initiated with the measured species concentrations at $t=14$ minutes. The starburst indicates the calculated end-of-burn value.

Figure 9. Measured and calculated temporal evolution of oxygen in the test chamber during Sunspot. The calculations are initiated with the measured species concentrations at $t=14$ minutes. The starburst indicates the calculated end-of-burn value 
Figure 10. Measured and calculated temporal evolution of nitrogen in the test chamber during Dazzler. The calculations are initiated with the measured species concentrations at $t=14$ minutes. The starburst indicates the calculated end-of-burn value...................................... 26

Figure 11. Measured and calculated temporal evolution of oxygen in the test chamber during Dazzler. The calculations are initiated with the measured species concentrations at $t=14$ minutes. The starburst indicates the calculated end-of-burn value.................................. 26 
List of Tables

Table 1: Discrete-Sample Lab MS Data from Rocket Motor Burns ........................... 18

Table 2: Calculated and Expected "End-of-Bum" Chamber Compositions........................2

\section{Nomenclature}

Ar argon

$\mathrm{Cl}_{2}$ chlorine gas

$\mathrm{CO}$ carbon monoxide

$\mathrm{CO}_{2}$ carbon dioxide

$\mathrm{HCl}$ hydrochloric acid

af absorption factor

$d f \quad$ dilution factor

GC gas chromatography

MS mass spectrometry

$n \quad$ moles (of gas)

NDIR non-dispersive infrared
$\mathrm{Kr} \quad$ krypton

$\mathrm{N}_{2}$ molecular nitrogen

NO nitric oxide

$\mathrm{O}_{2}$ molecular oxygen

$p \quad$ static pressure

$t$ time

t0 time at initiation of rocket motor burns

$\mathrm{t}=$ elapsed time from $\mathrm{t} 0$

$T$ temperature

$x \quad$ mole fraction

\section{Subscripts}

a air

$i \quad$ initial

$f \quad$ final

tot total 


\section{Executive Summary}

A series of contained explosive detonation and propellant burn experiments was conducted during 1996 and 1997 using a specially constructed, large, underground chamber located in the X-tunnel complex at Area 25 of the Nevada Test Site (NTS). The detonation tests employed 155-mm HE M107 projectiles and the propellant burn tests used NIKE M88 and Improved Hawk rocket motors. These experiments were performed as part of the Joint Demil Technology (JDT) Program between the Departments of Defense and Energy. An important goal of these experiments was characterization of the gaseous and particulate emissions associated with using typical disposal methods for excess munitions. Bechtel Nevada and Lawrence Livermore National Laboratory (LLNL) personnel sampled stable gas species through a few sampling ports in the test chamber. In most tests, the concentrations of $\mathrm{CO}_{2}$ decreased significantly as a function of time after the demil event while the concentrations of most other combustion products increased with time. LLNL personnel ascribed this behavior to $\mathrm{CO}_{2}$ absorption in the limecontaining chamber walls. The discrete-sampled, laboratory mass-spectrometry analyzed gas measurements are believed to be the most accurate, and therefore have been used to characterize the post-event chamber composition. Unfortunately, these gas samples were only collected periodically in time, with the first sample taken approximately 10 minutes after the detonation or burn test, requiring extrapolation of the measured species concentration temporal profiles back to the time at the end of burn. LLNL personnel used simplistic curve fits of this temporal data to deduce the initial gas mixture present in the chamber.

However, significant leak paths were observed to be present during the first two of the three rocket motor burn experiments. In addition, differences in the temporal behavior of some of the gas species concentrations are observed to occur at the time that the chamber pressure equilibrates with the ambient pressure for these tests. These observations suggest that dilution of chamber gases at late times by air may be an important mechanism affecting the measured gas concentration profiles. In the present work, an analytic framework for evaluating the relative influence of $\mathrm{CO}_{2}$ absorption and air dilution is developed and applied to the three rocket motor burn tests conducted in 1997. This methodology applies gas mole conservation laws to an enclosed volume in which $\mathrm{CO}_{2}$ absorption and/or air dilution is occurring and solves for the temporal evolution of the different chemical species. The measured temporal evolution of one or two species is used to compute the requisite absorption and/or dilution factors.

The calculated results for the largest of the three rocket motor burn tests, Thunderbird, demonstrate that the analysis is consistent with the measured species profiles if both $\mathrm{CO}_{2}$ absorption and air dilution are assumed to be active. At early times, the $\mathrm{CO}_{2}$ absorption effect dominates and the dilution factor is found to be negative, presumably as a consequence of inchamber mixing effects or finite sample line flushing effects. After the chamber pressure equilibrates with (or even falls below) the ambient pressure, the dilution factor is strongly positive, consistent with the expected air dilution effect, and dominates over $\mathrm{CO}_{2}$ absorption. The same trends are present during Sunpot, the smaller, first test, but the air dilution effect is an order of magnitude weaker than for Thunderbird. The $\mathrm{CO}_{2}$ absorption rate is $\sim 50 \%$ lower than for Thunderbird in this case, consistent with the $50 \%$ lower $\mathrm{CO}_{2}$ levels that are present. During the final test, Dazzler, no significant leakage occurred from the chamber, preventing air dilution effects, and almost no $\mathrm{CO}_{2}$ absorption is evident, either.

We have utilized the calculated early-time $\mathrm{CO}_{2}$ absorption rate to correct the initial species measurements, typically recorded at $\sim t=10$ minutes, for an improved estimation of the chamber 
composition at the end-of-burn. The end-of-burn concentrations deduced from this analysis show good consistency with the measured gas species temporal trends and give better agreement with the expected concentrations than those previously generated. The analytical expressions developed in this work may also be used for evaluation of species absorption or air dilution effects in other contained demil experiments. 


\section{Introduction}

A series of contained explosive detonation and propellant burn experiments was conducted during 1996 and 1997 using a specially constructed, large, underground chamber located in the X-tunnel complex at Area 25 of the Nevada Test Site (NTS) [LLNL Rpt UCRL-ID-131252; SNL Rpt SAND2000-8202]. The detonation tests employed 155-mm HE M107 projectiles and the propellant burn tests used NIKE M88 and Improved Hawk rocket motors. These experiments were performed as part of the Joint Demil Technology (JDT) Program between the Departments of Defense and Energy. The JDT Program is a collaborative effort to demonstrate and validate technologies for resource recovery, recycling, and alternative destruction/treatment technologies for waste munitions and rocket motors. The JDT Program is jointly managed by the Demil Technology Office in the Technology Directorate of the US Army Defense Ammunition Center, McAlester OK, and the US DOE Nevada Operations Office, Las Vegas NV. An important goal of these experiments was characterization of the gaseous and particulate emissions associated with using typical disposal methods for excess munitions. As a consequence, a large amount of instrumentation was utilized to characterize the overall chamber conditions (especially pressure and temperature) and to sample gases and particulates within the chamber before and after each demil event. A summary description of these tests and the results from the experimental measurements and observations is available in Bellow et al., 1998a and 1998b. The discrete-sampled, laboratory mass-spectrometry analyzed gas measurements are believed to be the most accurate, and therefore have been used to characterize the post-event chamber composition. Unfortunately, these gas samples were only collected periodically in time, with the first sample taken approximately 10 minutes after the detonation or burn test, requiring extrapolation of the measured species concentration temporal profiles back in time to make bestestimate predictions of the initial gas mixture present in the chamber at the end of the artillery shell detonations or rocket motor burns [Velsko et al., 1999]. This data analysis process is complicated by the apparent absorption of $\mathrm{CO}_{2}$ into chamber wall materials (either within the chamber itself or in the particulate-lined gas sampling lines). Another complicating factor, not accounted for in the original data analysis, relates to dilution of chamber gases by the air in the neighboring tunnel drift after the chamber pressure has fallen below the ambient pressure. In this report, we demonstrate that this effect was significant for two of the three low-pressure rocket motor burn tests (employing NIKE M88 and Improved Hawk rocket motors) and use this information to improve the prediction of the initial post-event gas mixture composition within the test chamber.

\section{Gas Sampling Data}

Extractive gas sampling and analysis were performed during the 1996 and 1997 Phase I (artillery shell detonation) and Phase II (rocket motor burn) tests by Bechtel Nevada and Lawrence Livermore National Laboratory (LLNL) personnel. The actual gas sampling configuration and its usage were modified during the course of the experimental series. During Phase I, samples were sequentially drawn from two sampling lines, one opening at the floor of the chamber (= "invert" in tunnel parlance) and the other approximately half way up the wall (= "rib"). Prior to Phase II, the wall sampling position was joined with the floor position, and an additional line opened on the chamber ceiling (= "back"); the sampling system allowed for discrete sampling from either of the two sample lines (the chamber roof or floor/wall), with continuous suction provided through each line. Unfortunately, the sampling line at the chamber roof became plugged during Thunderbird, the second of the 3 Phase II tests, so only the floor/wall line was 
available for sampling during that test. For all tests a drierite water knockout located in the tunnel drift was used to remove water vapor from the samples before collection or on-line analysis.

Sampled gases were continuously analyzed during the events using a variety of techniques: a portable gas chromatograph (GC), quadrupole mass spectrometer (Field MS), and several nondispersive infrared (NDIR) and chemiluminescent analyzers for individual species. In addition, at selected times before and after the demil events, discrete 1-liter "grab" samples were collected and analyzed remotely at LLNL using an analytical mass spectrometer (Lab MS). For the analysis presented here, only the data from the Lab MS are considered, because they are believed to have greater inherent accuracy than the other data and because their discrete nature is compatible with the type of analysis conducted here. The gas concentration values determined by the Lab MS generally agree with those determined in real time with the other techniques at NTS. Species concentrations measured by the Lab MS include $\mathrm{N}_{2}, \mathrm{O}_{2}, \mathrm{CO}_{2}, \mathrm{Ar}$, and $\mathrm{Kr}$ (introduced tracer).

\section{Test Chamber Leakage}

The instrumented containment plug that forms the seal between the test chamber and the tunnel drift was never intended to be fully gas-tight, but rather to provide sufficient containment to allow for extractive sampling of the product gases over a long enough time scale to permit characterization of the chamber gases. Leakage from the chamber into the tunnel drift was evidenced during the larger detonation experiments and the first two rocket motor burn experiments (Sunspot and Thunderbird). Video records from a camera in the tunnel drift focused on the containment plug during the rocket motor burn experiments indicate that the primary leakage paths from the test chamber were in areas near conduits used for electrical signal cables. Typically, these conduits passed under the containment plug in excavated channels that were subsequently sealed with pressurized grout. These seals evidently failed roughly 20 seconds after test initiation in both Sunspot and Thunderbird (i.e., the time when the peak pressure was reached in the test chamber), resulting in significant gas leakage from the chamber into the drift. After extensive grouting work was performed and additional steps taken to minimize leakage through the cable conduits, no signs of leakage were apparent during the final rocket motor burn test, Dazzler.

When significant gas leakage paths exist between the test chamber and the tunnel drift, it is quite likely that dilution of chamber gases with relatively fresh drift gases can substantially affect latetime gas concentration measurements in the chamber. Both the explosive detonations and rocket motor burns release large amounts of hot combustion products into the test chamber, thereby increasing the chamber pressure above the ambient from a combination of thermal and molar effects: for a fixed volume, the ideal gas law reduces to $p \propto n_{\text {tot }} T$. In a perfectly sealed inertwalled chamber, the gas temperature will slowly equilibrate with the surrounding (innermountain) temperature, and the final pressure will reflect the extra moles of material introduced into the gas phase during the demil events (i.e., the final pressure will be larger than the starting pressure). As shown in Figure 1, this ideal response is seen only in Dazzler, the last of the three rocket motor burn tests in Phase $\Pi$, where no known leakage from the chamber occurred. In contrast, the other two rocket motor burn tests, Sunspot and Thunderbird, actually show a drop in pressure below the initial value. This latter phenomenon results from substantial leakage from the chamber shortly after the end of the burns, when the chamber gases are still fairly hot and at high pressure. Whereas the drop in chamber pressure over time is dominated by cooling of the chamber gases (due to heat transfer to the chamber walls), gas leakage from the chamber allows 

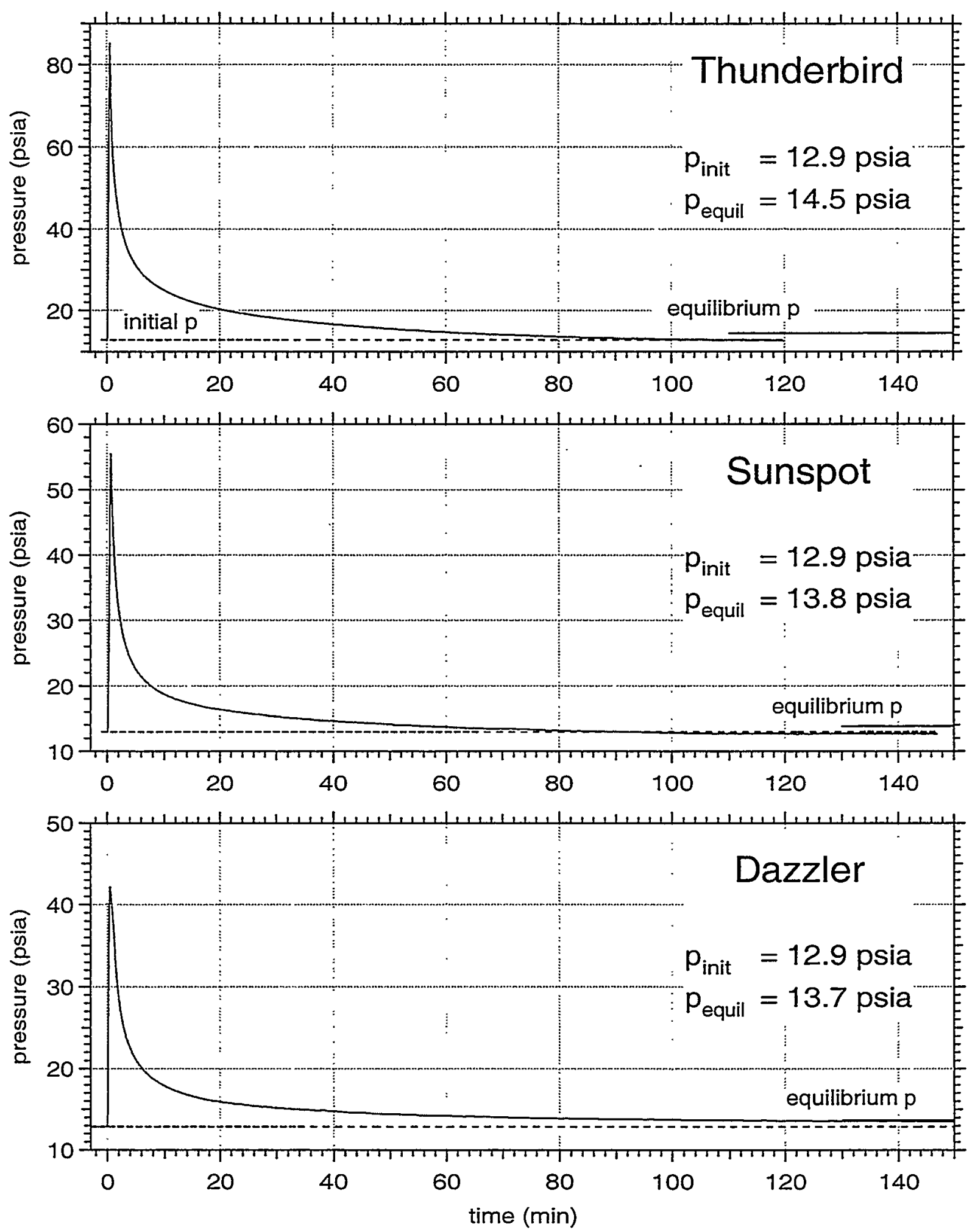

Figure 1. Chamber pressure histories during the rocket motor burn tests. Pre-shot chamber pressures are denoted by the dashed lines and the final, thermal equilibrium pressures (ignoring any leakage from the chamber or reactions with the walls) are also indicated. 
the chamber pressure to equilibrate with the pressure in the tunnel drift. This equilibration occurs even though the chamber gases are still at somewhat elevated temperatures. Further cooling of the chamber gases then leads to a reduction of chamber pressure below the ambient, and $a$ resultant reversal of flow from the drift to the chamber. Also, once the pressure gradient from the chamber to the drift is removed, natural convection flow paths may be established through the leak paths, with cooler air from the drift entering the bottom of the test chamber and warmer chamber gases flowing into the drift from leak paths originating higher in the chamber. Through the action of either or both of these mechanisms, one would expect contamination of the measured chamber gas concentrations by relatively fresh air from the drift.

\section{Absorption of $\mathrm{CO}_{2}$}

Velsko et al. [1999] noted a strong drop in the measured chamber $\mathrm{CO}_{2}$ concentration with time from from the end of burn for the Phase I tests and for all but the final test of Phase II. This apparent consumption of $\mathrm{CO}_{2}$ was attributed to absorption in the calcium-containing chamber walls, and thought to be the dominant contributor to temporal trends in the gas species data (except for NO, which is thought to be similarly reactive with the walls). As the analysis in this report will demonstrate, some absorption of $\mathrm{CO}_{2}$ did occur before the gas samples were collected or analyzed on-line. However, there is no unambiguous way of differentiating between absorption that occurs (1) directly into the actual test chamber walls, (2) on the extensive particulate mass suspended in the test chamber, or (3) on entrained or deposited particles inside the unheated, 300-m long gas sample lines. Analyses of the suspended particulate found it to be composed primarily of chamber materials (esp. calcium) during the Phase I tests and to have a significant contribution from chamber materials during Phase II. In fact, $\mathrm{CO}_{2}$ absorption onto calcium sources (to form calcium carbonate) occurs significantly more rapidly in the presence of liquid water, so one might expect the primary $\mathrm{CO}_{2}$ absorption effect to be within the sample lines, where the temperature is cooler than in the chamber, and water condensation is, therefore, more likely.

\section{Gas Analysis Implications}

One of the goals of the Phase I and Phase II JDT tests was to characterize the gas and particulate emissions from full-scale open-burn/open-detonation (OB/OD) events, using the containment provided by the X-tunnel test chamber to facilitate the relevant measurements. The measured gas concentrations after the demil event generally showed temporal variations, particularly for acidgas species such as $\mathrm{NO}$ and $\mathrm{CO}_{2}$, as noted previously. Also, significant time delays occurred between the actual demil event and when the the first discrete samples of gases were collected for later analysis with the laboratory mass spectrometer (the delays were typically $>10 \mathrm{~min}$ ). Consequently, the analysis by LLNL of the gas species concentrations relied on linear fits of the measured Lab-MS species concentrations vs. time to estimate the concentrations at the "end of burn". These predicted end-of-burn values then formed the basis of the overall characterization of the gas emissions from the different demil events. However, the data from Thunderbird show that some gas species, such as $\mathrm{O}_{2}$, show a distinct break in the temporal profile after $\mathrm{t}=100 \mathrm{~min}$. In these cases, the linear fitting approach to estimating the concentration at the end of burn appears doomed to fail, particularly if the late-time temporal variations are due to dilution of chamber gases by relatively fresh air from the tunnel drift. 


\section{Gas Concentration Analysis}

The approach taken in the analysis here is to apply species conservation expressions to the discrete-sampled Lab MS data to evaluate the measured temporal trends for compatibility with the $\mathrm{CO}_{2}$ surface absorption and air dilution hypotheses. The computational approach is initiated with the measured species concentrations at some point in time, uses one or more of the species profiles vs. time as an input (to calculate dilution and/or absorption factors), and then determines how the other species concentrations should vary with time. Leakage of chamber gases out of the chamber is not explicitly accounted for, as it is assumed that such leakage removes a certain number of moles of the local gas mixture and has no effect on its composition. For example, to determine the effect of air dilution on the measured $\mathrm{N}_{2}$ concentrations, we can incorporate the analysis presented below (see nomenclature table for the relevant variable definitions):

(a) air dilution

$$
\begin{aligned}
x_{N_{2}, i} & =\frac{n_{N_{2}, i}}{\sum n_{i}} \\
x_{N_{2}, f} & =\frac{n_{N_{2}, i}+n_{N_{2}, a}}{\sum n_{i}+\sum n_{a}}=\frac{n_{N_{2}, i}}{\sum n_{i}+\sum n_{a}}+\frac{n_{N_{2}, a}}{\sum n_{i}+\sum n_{a}} \\
& =x_{N_{2}, i} \cdot \frac{\sum n_{i}}{\sum n_{i}+\sum n_{a}}+x_{N_{2}, a} \cdot \frac{\sum n_{a}}{\sum n_{i}+\sum n_{a}}
\end{aligned}
$$

Define dilution factor, $\mathrm{df}$,

$$
\begin{aligned}
& \text { df } \equiv \frac{\sum n_{a}}{\sum n_{i}+\sum n_{a}} . \\
& \text { Then } x_{N_{2}, f}=x_{N_{2}, i} \cdot(1-d f)+x_{N_{2}, a} \cdot d f \\
& \text { and } d f=\frac{x_{N_{2}, f}-x_{N_{2}, i}}{x_{N_{2}, a}-x_{N_{2}, i}}
\end{aligned}
$$

For species not present in air, such as $\mathrm{Kr}$ (and, to a certain extent, $\mathrm{CO}_{2}$ ),

these expressions reduce to

$$
\begin{aligned}
& x_{K r, f}=x_{K r, i} \cdot(1-d f) \\
& \text { and } d f=\frac{x_{K r, i}-x_{K r, f}}{x_{K r, i}}
\end{aligned}
$$

Assuming that air dilution is the only relevant effect on the gas species concentrations during a given time duration after a demil test, these relations can be combined with the measured $\mathrm{CO}_{2}$ concentrations, for example, to solve for the dilution factor as a function of time; then the dilution factors can be used to predict the variation in the other gas concentrations as a function of time. Note that, as long as we allow for negative dilution factors, the analysis above can also treat the enrichment of measured combustion gases over time, for example due to flushing of residual air out of the sample lines or due to displacement or mixing of the initially air-rich volume near the sample probes in the test chamber with combustion products. 
Similar to the air dilution case, conservation equations can be written and solved to treat the effect of the absorption of $\mathrm{CO}_{2}$ on the concentrations of other gas species:

(b) $\mathrm{CO}_{2}$ absorption

$$
\begin{aligned}
& x_{\mathrm{CO}_{2}, i}=\frac{n_{\mathrm{CO}_{2}, i}}{\sum n_{i}} \\
& x_{\mathrm{CO}_{2}, f}=\frac{n_{\mathrm{CO}_{2}, f}}{\sum n_{f}}, \text { where } \sum n_{f}=\sum n_{i}-\left(n_{\mathrm{CO}_{2}, i}-n_{\mathrm{CO}_{2}, f}\right) \\
& \text { so } \frac{\sum n_{i}}{\sum n_{f}}=1+\frac{\left(n_{\mathrm{CO}_{2}, i}-n_{\mathrm{CO}_{2}, f}\right)}{\sum n_{f}}
\end{aligned}
$$

Define absorption factor, af,

$$
a f \equiv{\frac{\left(n_{\mathrm{CO}_{2}, i}-n_{\mathrm{CO}_{2}, f}\right)^{\prime}}{\sum n_{f}}}^{\prime}
$$

Then $\frac{\sum n_{i}}{\sum n_{f}}=1+a f=1+x_{\mathrm{CO}_{2}, i} \cdot \frac{\sum n_{i}}{\sum n_{f}}-x_{\mathrm{CO}_{2}, f}$

so $\frac{\sum n_{i}}{\sum n_{f}}=\frac{1-x_{\mathrm{CO}_{2}, f}}{1-x_{\mathrm{CO}_{2}, i}}$

and $a f=\frac{x_{\mathrm{CO}_{2, i}}-x_{\mathrm{CO}_{2, f}}}{1-x_{\mathrm{CO}_{2}, i}}$

For all species other than $\mathrm{CO}_{2}$ (such as $\mathrm{O}_{2}$ ),

$$
x_{O_{2}, f}=x_{O_{2}, i} \cdot \frac{\sum n_{i}}{\sum n_{f}}=x_{O_{2}, i} \cdot(1+a f)
$$

Note that for the $\mathrm{CO}_{2}$ absorption case, the $\mathrm{CO}_{2}$ concentration profiles must be used to calculate the absorption factor as a function of time; then the absorption factor may be used to calculate the variations in the other species concentrations in time, assuming $\mathrm{CO}_{2}$ absorption to be the dominant effect on the evolution of the species concentrations.

In general, we expect both air dilution and $\mathrm{CO}_{2}$ absorption effects to be operative, so we need to apply the following analysis:

(c) combined air dilution and $\mathrm{CO}_{2}$ absorption

$$
\begin{aligned}
& x_{N_{2}, i}=\frac{n_{N_{2}, i}}{\sum n_{i}} \\
& x_{N_{2}, f}=\frac{n_{N_{2}, i}+n_{N_{2}, a}}{\sum n_{f}+\sum n_{a}}=\frac{n_{N_{2}, i}+n_{N_{2}, a}}{\sum n_{i}-\Delta n_{C O_{2}}+\sum n_{a}}
\end{aligned}
$$




$$
=x_{N_{2}, i} \cdot \frac{\sum n_{i}}{\sum n_{i}-\Delta n_{C O_{2}}+\sum n_{a}}+x_{N_{2}, a} \cdot \frac{\sum n_{a}}{\sum n_{i}-\Delta n_{C O_{2}}+\sum n_{a}}
$$

Define the dilution factor, $\mathrm{df}$, in this case by

$d f \equiv \frac{\sum n_{a}}{\sum n_{i}-\Delta n_{C O_{2}}+\sum n_{a}}$

Then $\frac{\sum n_{i}}{\sum n_{i}-\Delta n_{C O_{2}}+\sum n_{a}}=1+\frac{\Delta n_{C O_{2}}-\sum n_{a}}{\sum n_{i}-\Delta n_{C O_{2}}+\sum n_{a}}$

$$
=1+a f-d f
$$

where af, the absorption factor, is defined in this case by

$a f \equiv \frac{\Delta n_{\mathrm{CO}_{2}}}{\sum n_{i}-\Delta n_{\mathrm{CO}_{2}}+\sum n_{a}}$

So $x_{N_{2}, f}=x_{N_{2}, i} \cdot(1+a f-d f)+x_{N_{2}, a} \cdot d f$

If we utilize the $\mathrm{O}_{2}$ measurements, for example, to yield information on $\mathrm{df}$ (we already must use the $\mathrm{CO}_{2}$ measurements to give af),

$$
d f=\frac{x_{\mathrm{O}_{2}, f}-(1+a f) x_{\mathrm{O}_{2, i}}}{x_{\mathrm{O}_{2}, a}-x_{\mathrm{O}_{2}, i}}
$$

Returning to the solution for the absorption factor,

$$
\begin{aligned}
& x_{\mathrm{CO}_{2}, f}=\frac{n_{\mathrm{CO}_{2}, i}-\Delta n_{\mathrm{CO}_{2}}+n_{\mathrm{CO}_{2}, a}}{\sum n_{i}-\Delta n_{\mathrm{CO}_{2}}+\sum n_{a}} \\
& =x_{\mathrm{CO}_{2}, i} \cdot(1+a f-d f)+x_{\mathrm{CO}_{2}, a} \cdot d f-a f \\
& \therefore \quad a f=\frac{x_{\mathrm{CO}_{2}, i}+d f\left(x_{\mathrm{CO}_{2}, a}-x_{\mathrm{CO}_{2}, i}\right)-x_{\mathrm{CO}_{2}, f}}{1-x_{\mathrm{CO}_{2}, i}} \\
& \text { and } d f=\frac{x_{\mathrm{O}_{2}, f}-x_{\mathrm{O}_{2}, i}\left(\frac{1+d f\left(x_{\mathrm{CO}_{2}, a}-x_{\mathrm{CO}_{2}, i}\right)-x_{\mathrm{CO}_{2}, f}}{1-x_{\mathrm{CO}_{2}, i}}\right)}{x_{\mathrm{O}_{2}, a}-x_{\mathrm{O}_{2}, i}} \\
& \text { so } d f\left(x_{\mathrm{O}_{2}, a}-x_{\mathrm{O}_{2}, i}+x_{\mathrm{O}_{2}, i} \frac{\left(x_{\mathrm{CO}_{2}, a}-x_{\mathrm{CO}_{2}, i}\right)}{1-x_{\mathrm{CO}_{2}, i}}\right)=x_{\mathrm{O}_{2}, f}-x_{\mathrm{O}_{2}, i}\left(\frac{1-x_{\mathrm{CO}_{2}, f}}{1-x_{\mathrm{CO}_{2}, i}}\right) \\
& \text { and } d f=\frac{x_{\mathrm{O}_{2}, f}-x_{\mathrm{O}_{2}, i}\left(\frac{1-x_{\mathrm{CO}_{2}, f}}{1-x_{\mathrm{CO}_{2}, i}}\right)}{x_{\mathrm{O}_{2}, a}-x_{\mathrm{O}_{2}, i}\left(\frac{1-x_{\mathrm{CO}_{2}, a}}{1-x_{\mathrm{CO}_{2}, i}}\right)}
\end{aligned}
$$


Note that, in this case, two separate species temporal profiles $\left(\mathrm{CO}_{2}\right.$ and one other) must be used to solve for the absorption and dilution factors simultaneously; then the remaining species concentration temporal profiles may be calculated.

The measured $\mathrm{O}_{2}$ concentration profile for Thunderbird shows an early decrease, which is inconsistent with the $\mathrm{CO}_{2}$ absorption effect that may be expected to dominate at those times. Other possible explanations include inner-chamber mixing (which may be expected to be replacing air-rich gases near the edges of the chamber with more product-rich gases from the center of the chamber) or simultaneous $\mathrm{CO}_{2}$ absorption and $\mathrm{O}_{2}$ chemisorption into the wall material. Therefore, an analysis was developed for the combination of air dilution and $\mathrm{CO}_{2}$ and $\mathrm{O}_{2}$ absorption, utilizing three separate species profiles $\left(\mathrm{CO}_{2}, \mathrm{O}_{2}\right.$, and another) as input data. The results of this analysis of the Thunderbird data were not very promising (i.e., oxygen chemisorption does not appear to be significant), so the relations for this special case are not presented here.

\section{Results and Implications}

The discrete-sample, Lab MS data from the three rocket motor burn tests in Phase II of the JDT X-Tunnel experiments in 1997 are reproduced in Table 1. Although Sunspot was the first of the Phase II tests, the results for Thunderbird are presented first because this test involved the most propellant and clearly had significant leakage from the test chamber, so it is the best case to use for examining the validity of the analytical procedures described in the previous section.

\section{Thunderbird}

Gas sampling after the combustion of 4 NIKE rocket motors (a total of $3000 \mathrm{lbs}$ of double-base propellant) in the X-tunnel test chamber shows monotonic increases in the $\mathrm{N}_{2}$ and $\mathrm{Ar}$ concentrations and monotonic decreases in the $\mathrm{CO}_{2}$ concentration with time, as would be expected if either $\mathrm{CO}_{2}$ were being absorbed onto surfaces or if air were diluting the original chamber gases. The $\mathrm{O}_{2}$ concentration initially drops and then ultimately rises, with the initial reduction in $\mathrm{O}_{2}$ potentially due to in-chamber mixing effects or chemisorption of the $\mathrm{O}_{2}$ onto surfaces. The $\mathrm{Kr}$ time profile is especially informative, as it shows an initial increase, up to a peak in the vicinity of 80-110 minutes, followed by a strong decay after 110 minutes. This behavior is consistent with species absorption dominating up to 110 minutes (tending to drive up the concentration of those species not being absorbed into surfaces) and air dilution dominating after that (tending to decrease the concentration of those species with lower concentrations in air). This turnover point corresponds to the time at which the measured chamber pressure equilibrates with the ambient, thereby removing the pressure-driven chamber outflow through the various leak paths.

Some of the results of analytical calculations using the data from Thunderbird are illustrated in Figs. 2 \& 3. Note that the discrete-sample MS data and the calculations are all performed on a dry basis (assuming all water is removed from the sample in question). Also, the measured preshot chamber gas composition is assumed to be the same as that in the adjacent tunnel drift and is used for the air dilution calculations. Figure 2 illustrates the krypton data trend that offers strong evidence of air dilution effects at late sample times, after the chamber pressure has equilibrated. The lines emanating from the data point at 80 minutes are the results of calculations using the measured $\mathrm{CO}_{2}$ concentrations and making the assumption that the temporal variation in $\mathrm{CO}_{2}$ after $\mathrm{t}=80 \mathrm{~min}$ is due to $\mathrm{CO}_{2}$ absorption, air dilution, or a combination of the two effects. The 
Table 1: Discrete-Sample Lab MS Data from Rocket Motor Burns

\begin{tabular}{|c|c|r|r|r|r|r|}
\hline \multirow{2}{*}{ Test/time (min) } & \multicolumn{7}{|c|}{ Gas Concentration (vol-\%) } \\
& $\mathrm{N}_{2}$ & $\mathrm{O}_{2}$ & $\mathrm{CO}_{2}$ & $\mathrm{Ar}$ & $\mathrm{Kr}$ & Total \\
\hline Thunderbird & & & & & & \\
-73 & 77.61 & 21.43 & 0.02 & 0.93 & 0.01 & 100.00 \\
14 & 74.06 & 5.97 & 18.87 & 0.85 & 0.20 & 99.95 \\
42 & 75.04 & 5.86 & 17.70 & 0.86 & 0.20 & 99.66 \\
80 & 75.70 & 5.38 & 17.80 & 0.86 & 0.21 & 99.95 \\
110 & 76.15 & 5.64 & 16.77 & 0.87 & 0.21 & 99.64 \\
157 & 76.96 & 7.38 & 14.23 & 0.89 & 0.18 & 99.64 \\
199 & 77.59 & 8.49 & 12.80 & 0.89 & 0.17 & 99.94 \\
\hline Sunspot & & & & & & \\
-70 & 77.89 & 21.17 & 0.03 & 0.91 & 0.00 & 100.00 \\
14 & 75.84 & 13.47 & 9.59 & 0.87 & 0.24 & 100.00 \\
52 & 76.30 & 13.45 & 9.16 & 0.87 & 0.22 & 100.00 \\
87 & 76.49 & 13.44 & 8.98 & 0.87 & 0.23 & 100.00 \\
115 & 76.82 & 13.50 & 8.59 & 0.87 & 0.22 & 100.00 \\
154 & 77.06 & 13.72 & 8.15 & 0.86 & 0.22 & 100.00 \\
217 & 77.51 & 13.77 & 7.64 & 0.87 & 0.22 & 100.01 \\
\hline Dazzler & & & & & & \\
-27 & 77.89 & 21.15 & 0.03 & 0.91 & 0.00 & 99.98 \\
7 & 77.55 & 16.81 & 4.30 & 0.87 & 0.22 & 99.92 \\
35 & 77.46 & 16.79 & 4.44 & 0.87 & 0.22 & 99.96 \\
67 & 77.54 & 16.75 & 4.40 & 0.87 & 0.21 & 99.96 \\
95 & 77.55 & 16.77 & 4.38 & 0.87 & 0.22 & 99.96 \\
127 & 77.56 & 16.84 & 4.31 & 0.86 & 0.20 & 99.95 \\
163 & 77.67 & 16.79 & 4.26 & 0.87 & 0.22 & 99.99 \\
\hline
\end{tabular}

Notes on Table 1:

(a) the data shown in Table 1 are reproduced from the final project report by Velsko et al. [1999], except the final sample time for Sunspot has been corrected from the final report by Velsko, and the data for every other sampling time for Sunspot have been corrected for a $7 \%$ air dilution of the samples to give consistent trends; Velsko et al. noted the apparent sample air contamination problem in the original data.

(b) the total gas vol-\% concentrations on the right of the table are simply the summation of the Lab MS species concentrations and are not meant to be an indicator of overall measurement consistency, since significant quantities of some other gas species, such as $\mathrm{CO}$ (and $\mathrm{Cl}_{2}$ and $\mathrm{HCl}$ for Dazzler) are known to be produced during these tests. The gas total shown for Dazzler includes the measured concentration of neon tracer gas introduced during this test.

(c) quoted instrumental measurement uncertainties (in vol-\%) are approximately as follows for the species concentrations present during these tests: $\mathrm{N}_{2}, 0.10 ; \mathrm{O}_{2}, 0.02 ; \mathrm{CO}_{2}, 0.03$; $\mathrm{Ar}, 0.01 ; \mathrm{Kr}, 0.01$. 


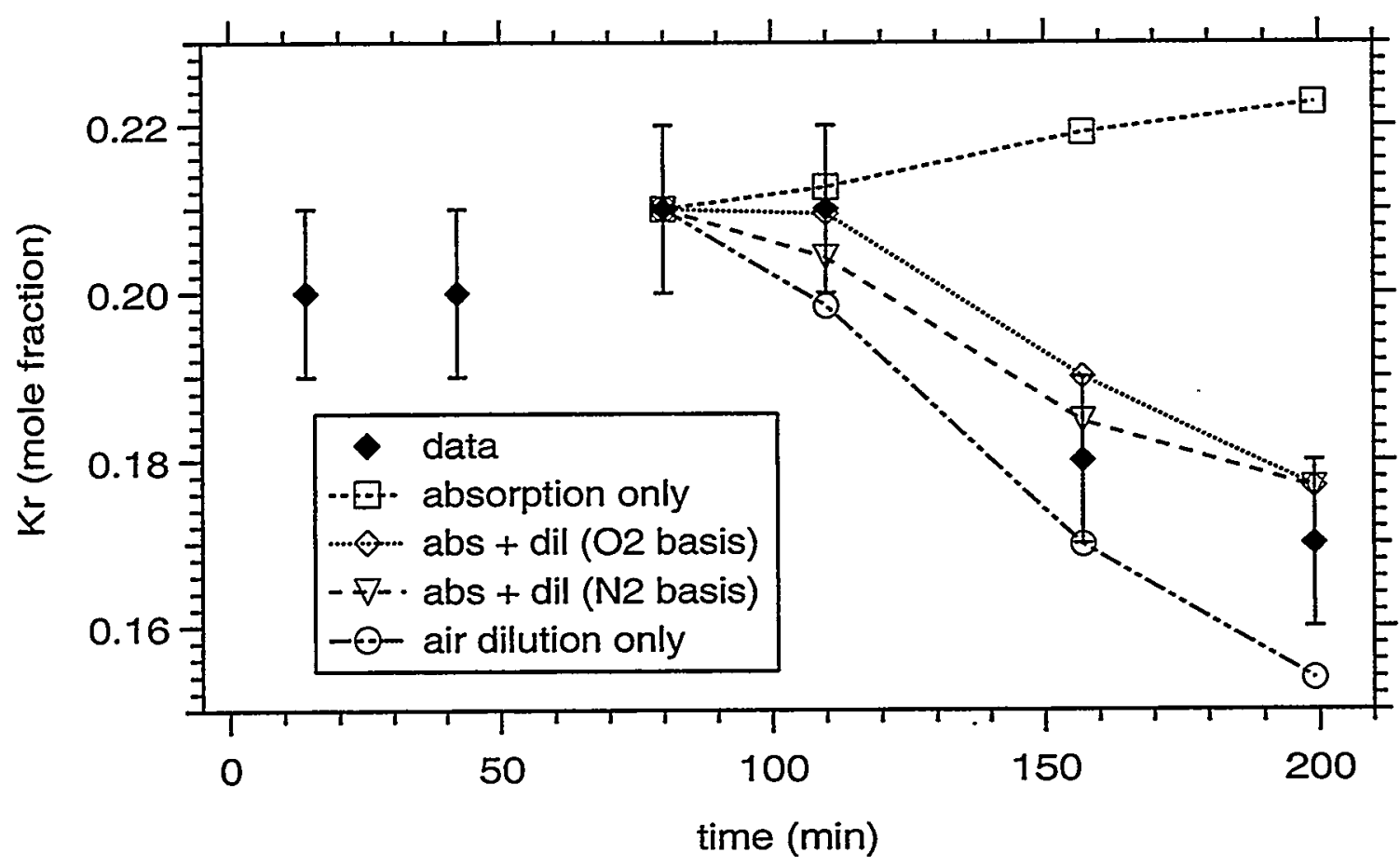

Figure 2. Measured and calculated temporal evolution of krypton in the test chamber during Thunderbird. The calculations are initiated with the measured species concentrations at $\mathrm{t}=80$ minutes. Error bars indicate measurement uncertainty.

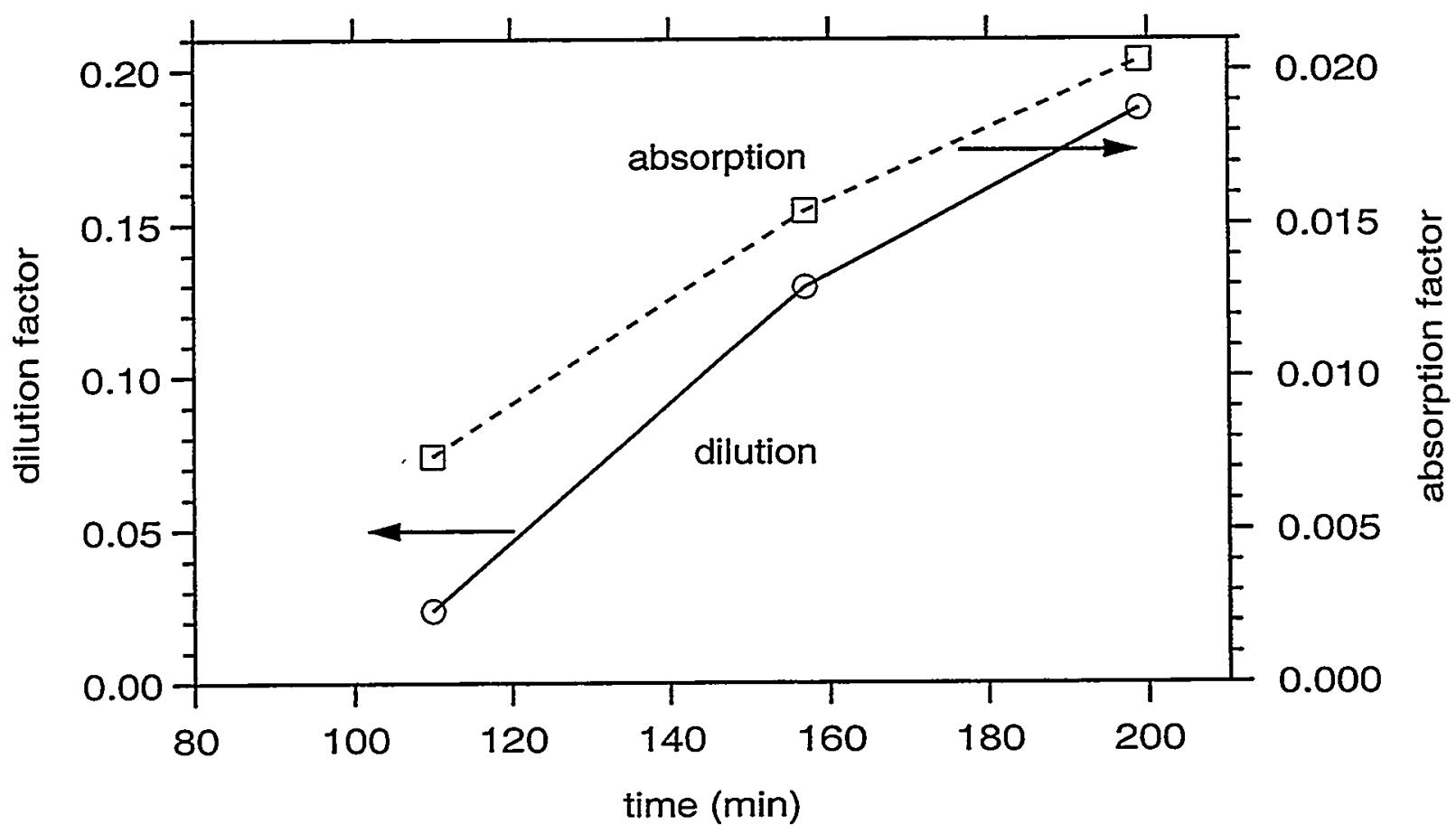

Figure 3. Air dilution factors and $\mathrm{CO}_{2}$ absorption factors from the combined effects calculation during the latter sample times of Thunderbird. The calculations are initiated with the measured species concentrations at $t=80$ minutes. 
assumption of $\mathrm{CO}_{2}$ absorption only shows a nearly linear increase in $\mathrm{Kr}$ concentration after 80 min, in stark contrast to the decreasing trend of the data. Conversely, an assumption that all of the $\mathrm{CO}_{2}$ variation after $80 \mathrm{~min}$ is due solely to air dilution effects overpredicts the measured decline in $\mathrm{Kr}$ concentration. The assumption of simultaneous $\mathrm{CO}_{2}$ absorption and air dilution shows the best agreement, with slightly different results depending on whether the measured $\mathrm{N}_{2}$ profile or the measured $\mathrm{O}_{2}$ profile is used to provide the second input value to the calculation. The limited precision of the $\mathrm{Kr}$ data ( 0.01 vol-\%) makes detailed comparisons of the recorded data and the calculated values impractical, but the results shown in Fig. 2 clearly support the validity of a combined air dilution/ $\mathrm{CO}_{2}$ absorption analysis in interpreting the data trends after the chamber pressure has equilibrated with the tunnel drift.

The values of the dilution factor (the fraction of the sampled volume occupied by diluting air) and the absorption factor (the volume of $\mathrm{CO}_{2}$ absorbed relative to the sampled volume) determined by the combined effects calculation are shown in Fig. 3, where an average has been taken of the factors calculated from using the $\mathrm{N}_{2}$ or $\mathrm{O}_{2}$ profile for the required data input to the calculation. Both factors demonstrate a nearly linear increase after $t=80 \mathrm{~min}$, suggesting that air dilution and $\mathrm{CO}_{2}$ absorption are occurring at nearly constant rates during this time interval. By the final sampling point, nearly $20 \%$ of the sampled gas is dilution air. The dilution factor is nearly an order of magnitude greater than the absorption factor, but since the concentration of $\mathrm{CO}_{2}$ during this time period is between $13 \%$ and $18 \%$, the effect of absorption on the $\mathrm{CO}_{2}$ profile itself is almost as large as the effect of air dilution.

Figure 4 shows the results for $\mathrm{N}_{2}$ concentration, when using the measured data at $\mathrm{t}=80 \mathrm{~min}$ as the starting point for the different calculations. For nitrogen, both the absorption and dilution assumptions lead to increased concentrations, but the absorption assumption overestimates the increase and the dilution assumption underestimates it. A combined absorption and dilution assumption (using the measured $\mathrm{CO}_{2}$ and $\mathrm{O}_{2}$ concentrations as inputs) leads to fairly accurate trending of the $\mathrm{N}_{2}$ concentration with time. The results and trends for argon are very similar to those shown for $\mathrm{N}_{2}$. Figure 5 shows the results when using the first measured concentration after $\mathrm{t} 0$ (at $\mathrm{t}=14 \mathrm{~min}$ ) to initiate the calculations. In this case, the same general trends with the different assumptions continue to hold, but the dilution factor for the combined effects case is slightly negative for $\mathrm{t} \leq 110 \mathrm{~min}$. At first appearance, one might assume that a negative dilution factor is physically impossible (tantamount to extracting air from a gas mixture), but in reality the calculated negative dilution factors may reflect in-chamber mixing (wherein air-rich initial mixtures near the wall are replaced by fully-mixed products) or long-timescale removal of the remnants of the air that initially filled the sample lines. When the chamber pressure equilibrated (at $\sim \mathrm{t}=100 \mathrm{~min}$ ) and air dilution into the chamber was initiated, the actual air dilution dominated over any remaining chamber mixing or air displacement effects and the calculated dilution factor properly reflects this.

Figures 6 and 7 show the oxygen concentration data and the calculated trends for $\mathrm{CO}_{2}$ absorption and air dilution assumptions, when initiating the calculation at the time when actual air dilution is expected to begin and also shortly after the rocket motor burn. In both cases, the combined absorption and dilution assumption best mirrors the data trends, and the effective negative dilution during early times recovers the drop in $\mathrm{O}_{2}$ concentration that is apparent in the data.

Comparisons of the calculated evolution of species concentrations with those actually measured during Thunderbird clearly show that both $\mathrm{CO}_{2}$ absorption and air dilution have a significant impact. The present calculations also indicate that the air dilution factor has a strong temporal variation, as one would expect, and is effectively negative at early sampling times. Therefore, 


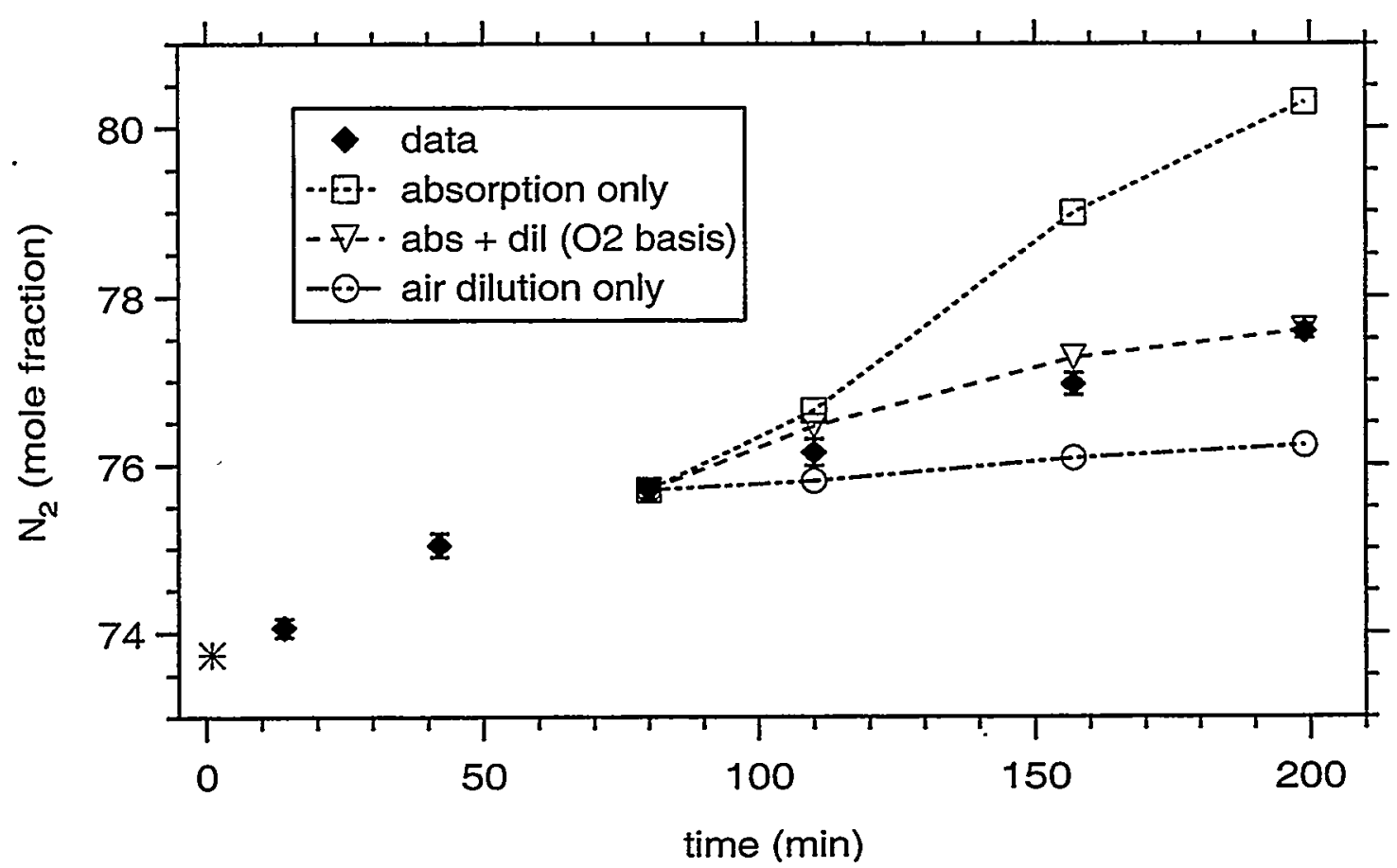

Figure 4. Measured and calculated temporal evolution of nitrogen in the test chamber during Thunderbird. The calculations are initiated with the measured species concentrations at $t=80$ minutes. The starburst indicates the calculated end-ofburn value.

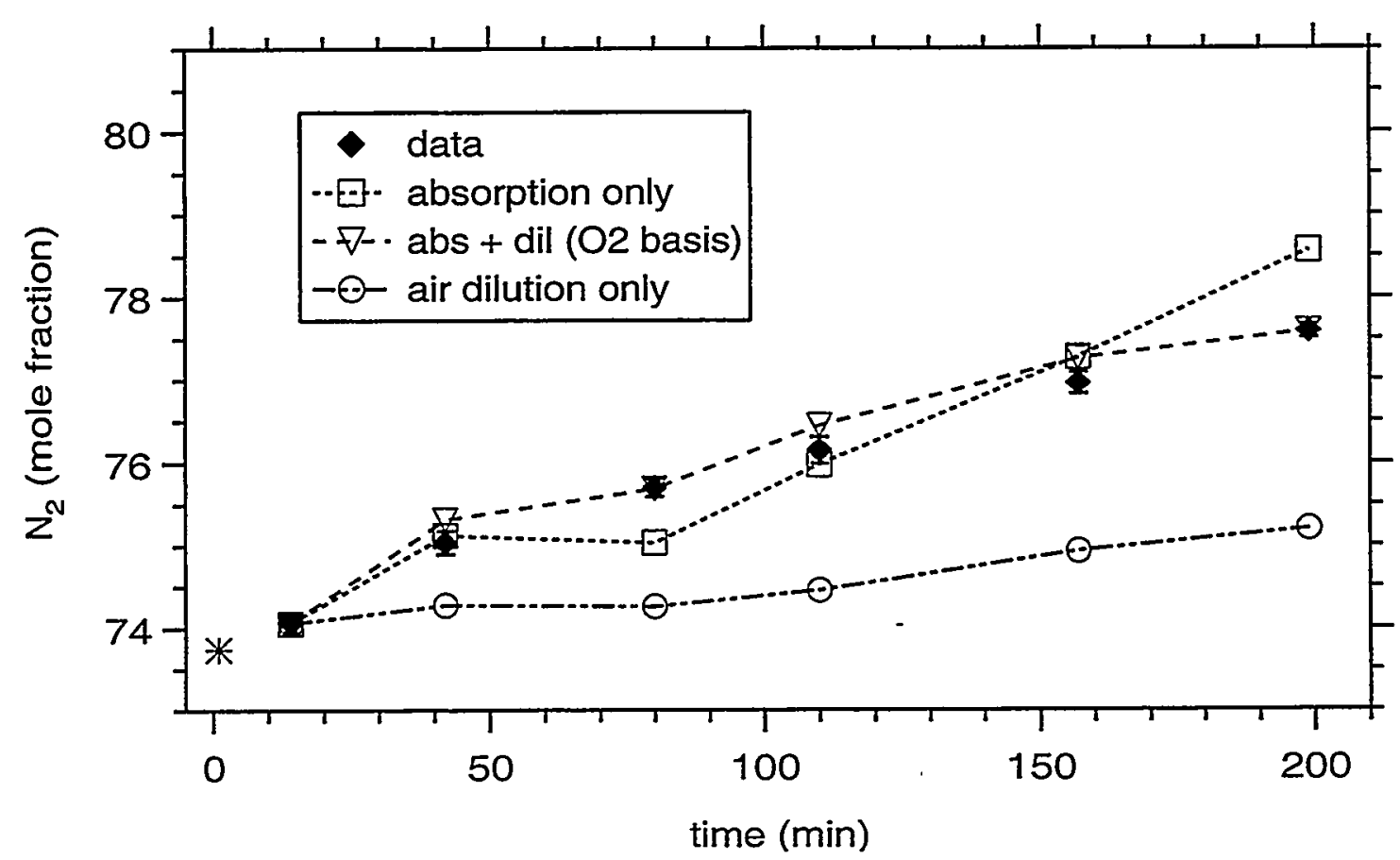

Figure 5. Measured and calculated temporal evolution of nitrogen in the test chamber during Thunderbird. The calculations are initiated with the measured species concentrations at $t=14$ minutes. The starburst indicates the calculated end-ofburn value. 


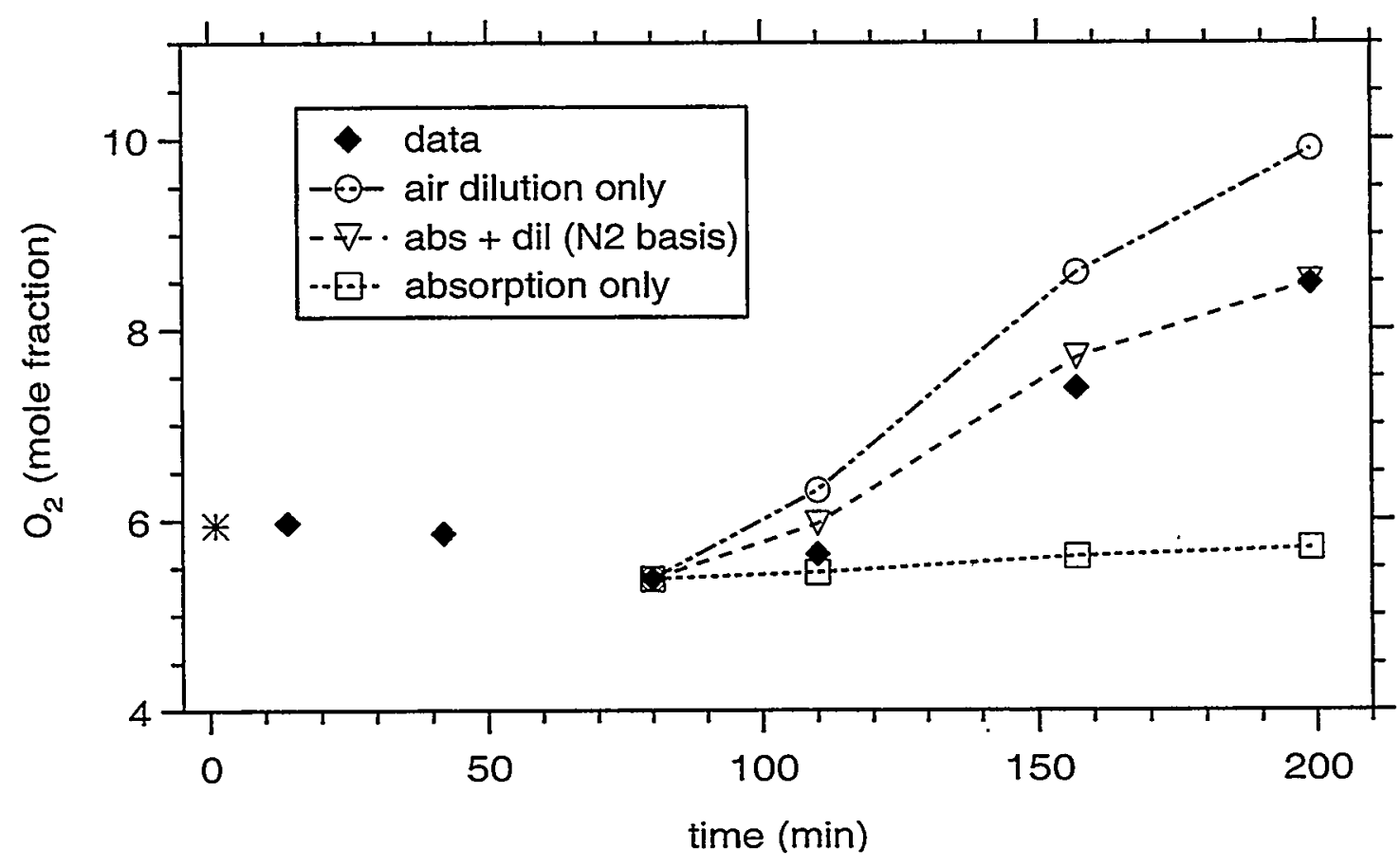

Figure 6. Measured and calculated temporal evolution of oxygen in the test chamber during Thunderbird. The calculations are initiated with the measured species concentrations at $t=80$ minutes. The starburst indicates the calculated end-ofburn value.

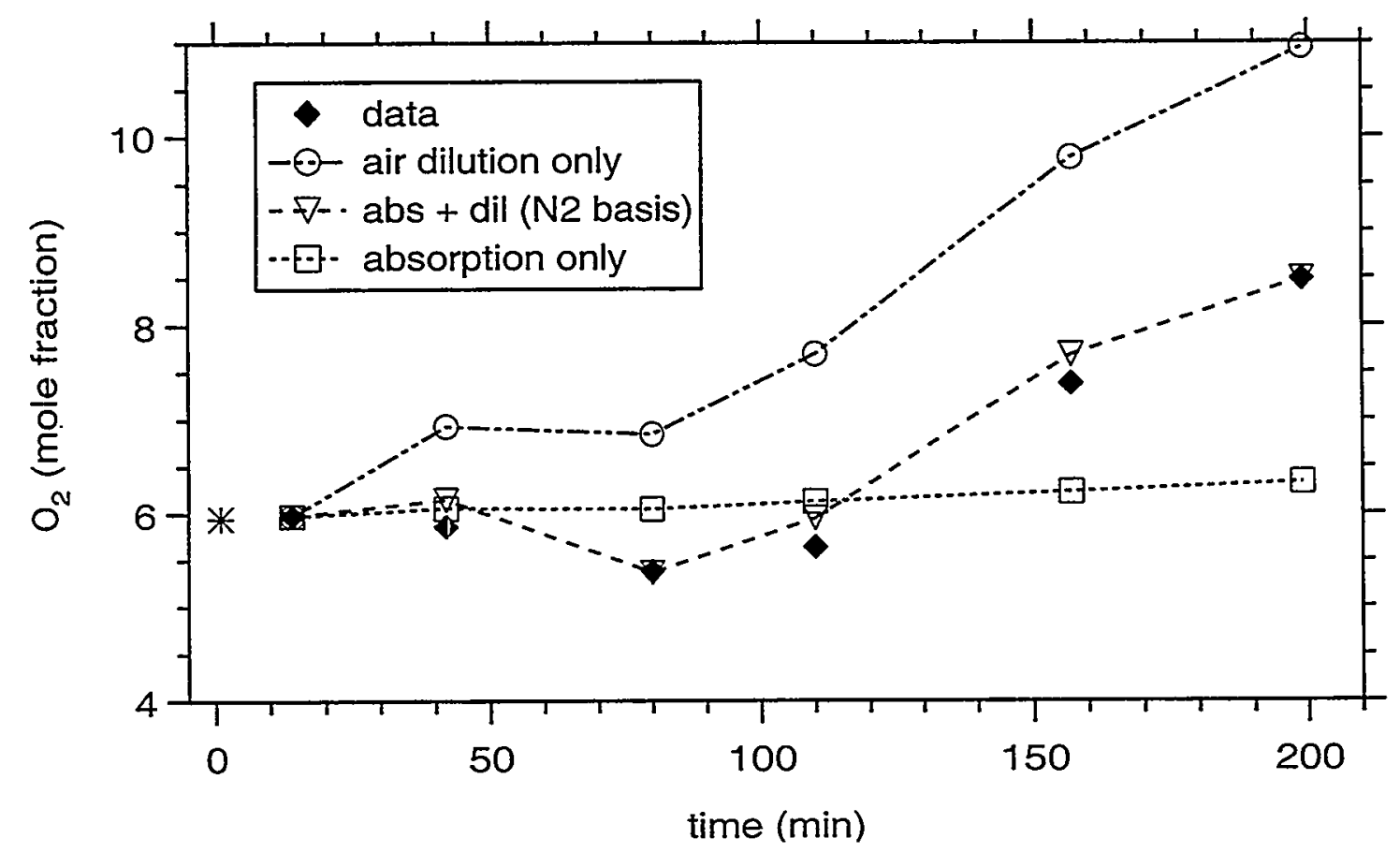

Figure 7. Measured and calculated temporal evolution of oxygen in the test chamber during Thunderbird. The calculations are initiated with the measured species concentrations at $t=14$ minutes. The starburst indicates the calculated end-ofburn value. 
extrapolations of the measured profiles to end-of-burn values should rely heavily on the earlytime sample data, before significant air dilution has occurred. A cubic polynomial function gives a good fit of the calculated absorption factors as a function of time, allowing a prediction of the absorption rate during the time period between the end-of-burn and the first gas sampling. Using this information, the first discrete-sample Lab MS concentrations can be used to calculate the end-of-burn values. These are shown in Figs. 4-7 and in Table 2, where they are compared to the "expected" values calculated by LLNL. For both the present calculations and those performed by LLNL, the end-of-burn time is assumed to be at $t=1 \mathrm{~min}$ from the time of explosive ignition of the rockets. As Table 2 demonstrates, the end-of-burn values that we have calculated agree better with both the measured data trends and the expected values than the linear-

Table 2: Calculated and Expected "End-of-Burn" Chamber Compositions

\begin{tabular}{|c|c|c|c|c|c|c|}
\hline Test/time (min) & \multicolumn{7}{|c|}{ Gas Concentration (vol-\%) } \\
& $\mathrm{N}_{2}$ & $\mathrm{O}_{2}$ & $\mathrm{CO}_{2}$ & $\mathrm{Ar}$ & $\mathrm{Kr}$ & Total \\
\hline Thunderbird & & & & & & \\
LLNL linear fit & 74.09 & 5.03 & 19.63 & 0.85 & 0.21 & 99.81 \\
LLNL "best fit" & 75.13 & 4.48 & 19.01 & 0.85 & 0.20 & 99.67 \\
present analysis & 73.74 & 5.94 & 19.22 & 0.85 & 0.20 & 99.95 \\
"expected" & 73.2 & 6.75 & 19.00 & 0.84 & 0.20 & 99.99 \\
\hline Sunspot & & & & & & \\
LLNL linear fit & 75.89 & 13.79 & 9.23 & 0.87 & 0.22 & 100.00 \\
LLNL "best fit" & 75.63 & 13.14 & 9.95 & 0.87 & 0.22 & 99.81 \\
present analysis & 75.74 & 13.45 & 9.70 & 0.87 & 0.24 & 100.00 \\
"expected" & 75.42 & 13.45 & 10.01 & 0.88 & 0.23 & 99.99 \\
\hline Dazzler & & & & & & \\
LLNL linear fit & 77.48 & 16.79 & 4.40 & 0.87 & 0.22 & 99.76 \\
LLNL "best fit" & 77.10 & 16.20 & 4.17 & 0.90 & 0.20 & 98.57 \\
present analysis & 77.55 & 16.81 & 4.30 & 0.87 & 0.22 & 99.75 \\
"expected" & 76.45 & 16.22 & 4.10 & 0.90 & 0.22 & 97.89 \\
\hline
\end{tabular}

Notes on Table 2:

(a) the "LLNL linear fit" values are the linear fit extrapolations of the Lab MS data to $t=1$ minute after initiation of the rocket motor burns (as listed in Velsko et al. [1999]).

(b) the "LLNL "best fit" values are selected combinations of the extrapolations of the Lab MS data, Field MS data, portable GC data, and $\mathrm{O}_{2}$ analyzer data to $t=1$ minute after initiation of the rocket motor burns (as listed in Velsko et al. [1999]).

(c) the "expected" values are those calculated by Velsko et al. [1999] when performing a detailed inventory of all combustible materials in the rocket motors and assuming full conversion to final product species. For Dazzler, the expected values listed are those when assuming all of the chlorine is converted in $\mathrm{HCl}$.

(d) the "total" column simply lists the algebraic sum of the major species listed in this table, and does not account for the use of neon tracer gas and the release of chlorinated species during Dazzler, or for the formation of $\mathrm{CO}, \mathrm{H}_{2}$, NOx, and other trace species during any of the tests. 
fit derived values calculated previously by LLNL researchers. In comparison with the LLNL "best fit" values, our calculated end-of-burn values show similar extents of variation relative to the expected concentrations (which have their own assumptions and finite uncertainty).

\section{Sunspot}

The same analysis described in the preceding subsection for Thunderbird was performed for the Sunspot event, in which 2 NIKE motors (containing a total of $1500 \mathrm{lbs}$ of propellant) were cracked and burned. In this case, the chamber pressure equilibrated with the ambient at approx. $90 \mathrm{~min}$, similar to the case of Thunderbird, such that air dilution effects may be expected after this time. The smaller deviations in the molecular composition, both as a direct consequence of the rocket motor burn and as a function of time after the burn, make interpretation of these calculations more difficult than was the case for Thunderbird. In general, however, the same trends found in the analysis of the Thunderbird data are also present for Sunspot. The measured $\mathrm{N}_{2}$ and $\mathrm{O}_{2}$ gas concentrations and the results of the full-time calculations are shown in Figures 8 and 9.

Figures 8 and 9 indicate that for Sunspot, absorption of $\mathrm{CO}_{2}$ is the dominant factor affecting the evolution of the gas species concentrations. As with Thunderbird, at early times, a negative dilution factor is calculated and is necessary to accurately reconstruct the data trends (particularly for $\mathrm{O}_{2}$ ). The calculations indicate that the absorption factor increases approximately linearly with time (i.e., the molecular absorption rate is constant) and is about $1 / 2$ of the magnitude seen in Thunderbird, which is consistent with the $50 \%$ lower $\mathrm{CO}_{2}$ concentrations in Sunspot, relative to Thunderbird. The late-time calculated dilution factors are an order of magnitude smaller than for Thunderbird, which may reflect the presence of smaller leak paths for Sunspot and/or the significantly higher chamber temperatures during Thunderbird (driving the natural convection that helps bring dilution air into the chamber). By the end of sampling, the calculations suggest that $1-2 \%$ of the sampled gas is dilution air and that $>2 \%$ of the chamber gases have been absorbed. The nominally constant apparent absorption rate is used to correct the initially sampled species concentrations to determine "end-of-burn" values, as shown in Figs. 8 \& 9 and in Table 2.

\section{Dazzler}

For Dazzler, no significant leakage from the test chamber was observed, and the molecular concentrations remained fairly constant over time. Consequently, calculations assuming $\mathrm{CO}_{2}$ absorption or air dilution or simultaneous operation of these two effects yielded roughly similar results (see Figs. 10 \& 11). The calculated absorption factors are an order of magnitude lower than those calculated for Sunspot and the calculated dilution factors are very small and generally negative. For these reasons, and because the first data point is only at $t=7 \mathrm{~min}$, the best estimate of the "end-of-burn" composition would seem to be the actual measured values at $t=7 \mathrm{~min}$; this is what is shown in Figs. $10 \& 11$ and Table 2. 


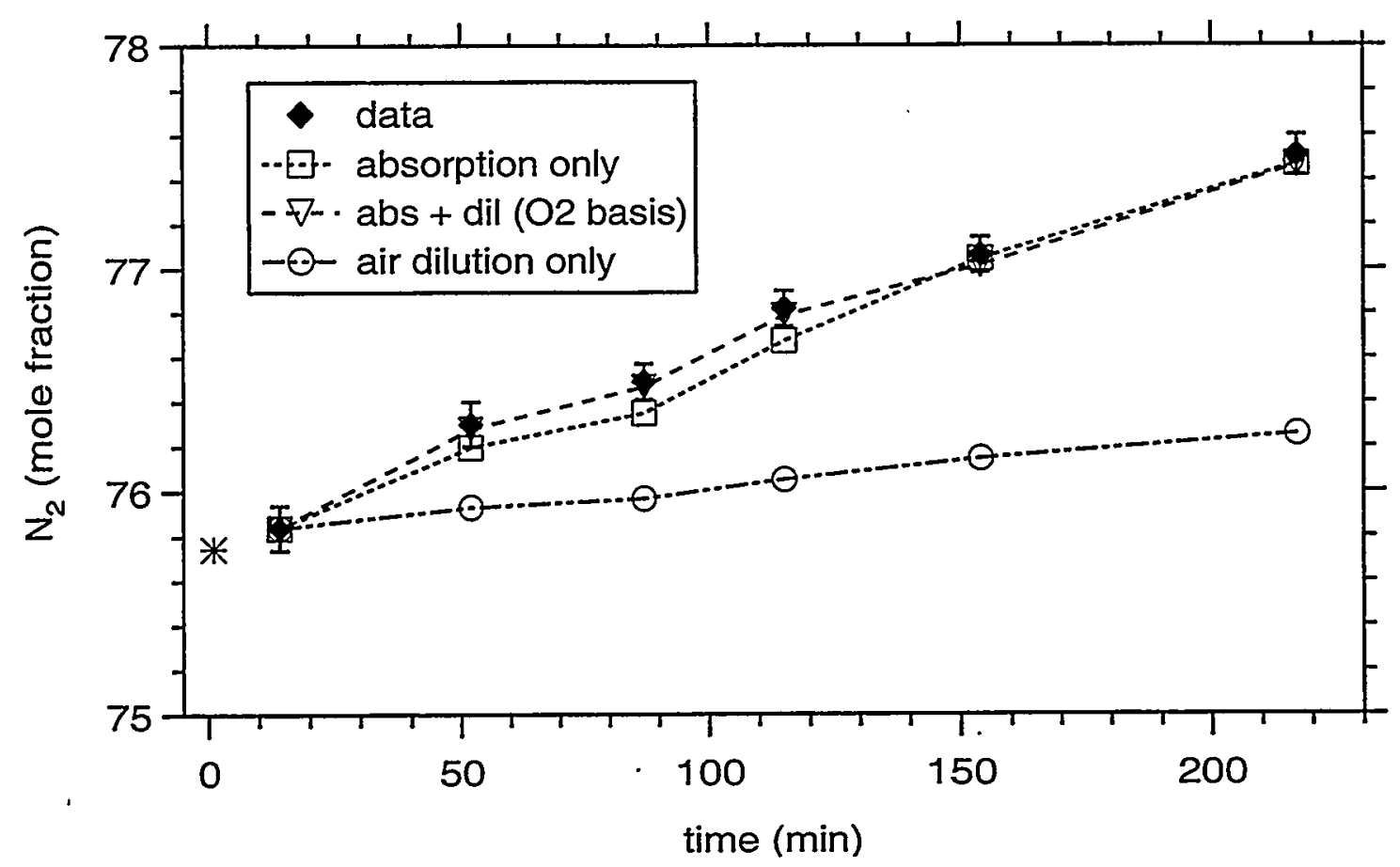

Figure 8. Measured and calculated temporal evolution of nitrogen in the test chamber during Sunspot. The calculations are initiated with the measured species concentrations at $t=14$ minutes. The starburst indicates the calculated end-ofburn value.

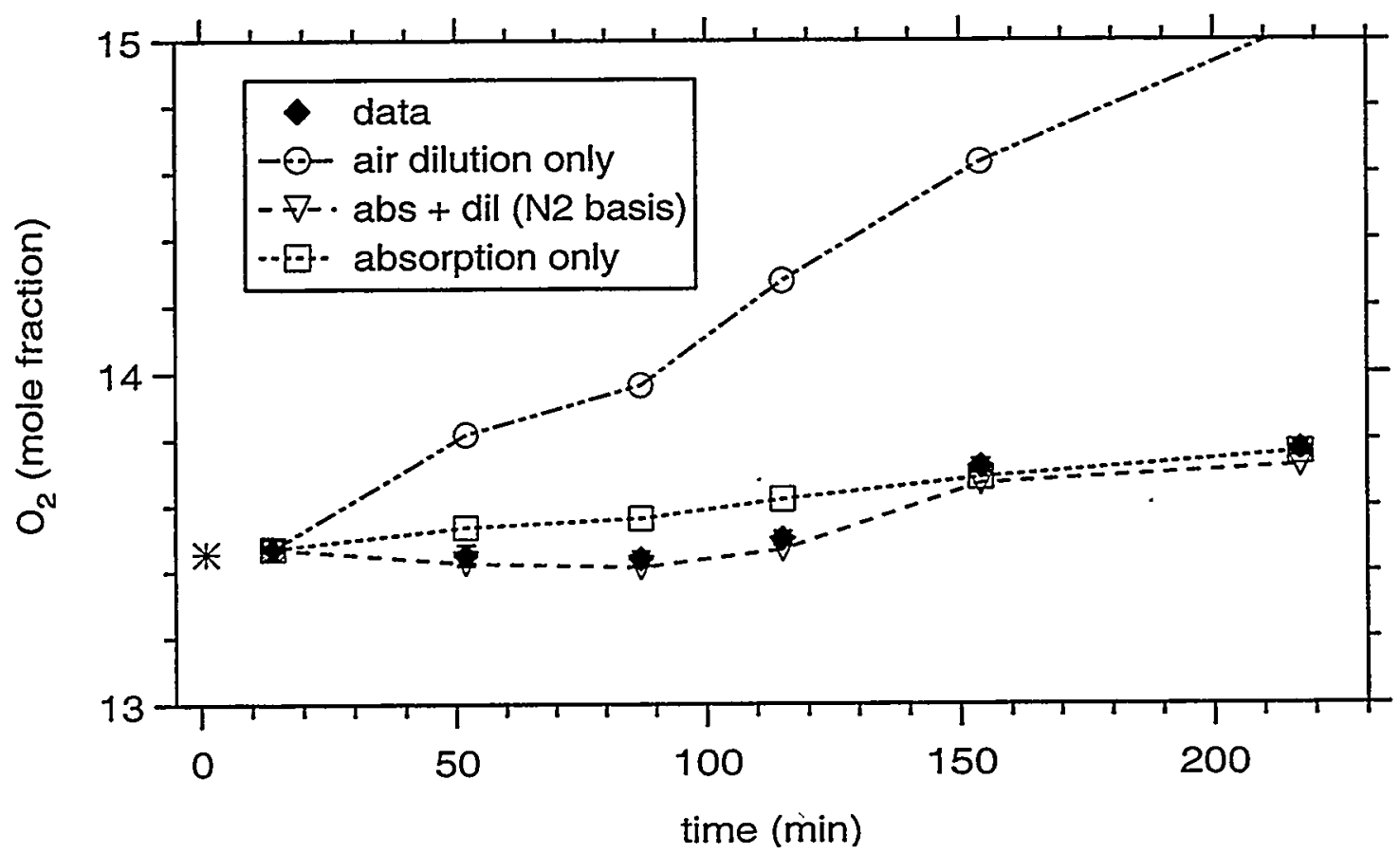

Figure 9. Measured and calculated temporal evolution of oxygen in the test chamber during Sunspot. The calculations are initiated with the measured species concentrations at $t=14$ minutes. The starburst indicates the calculated end-ofburn value. 


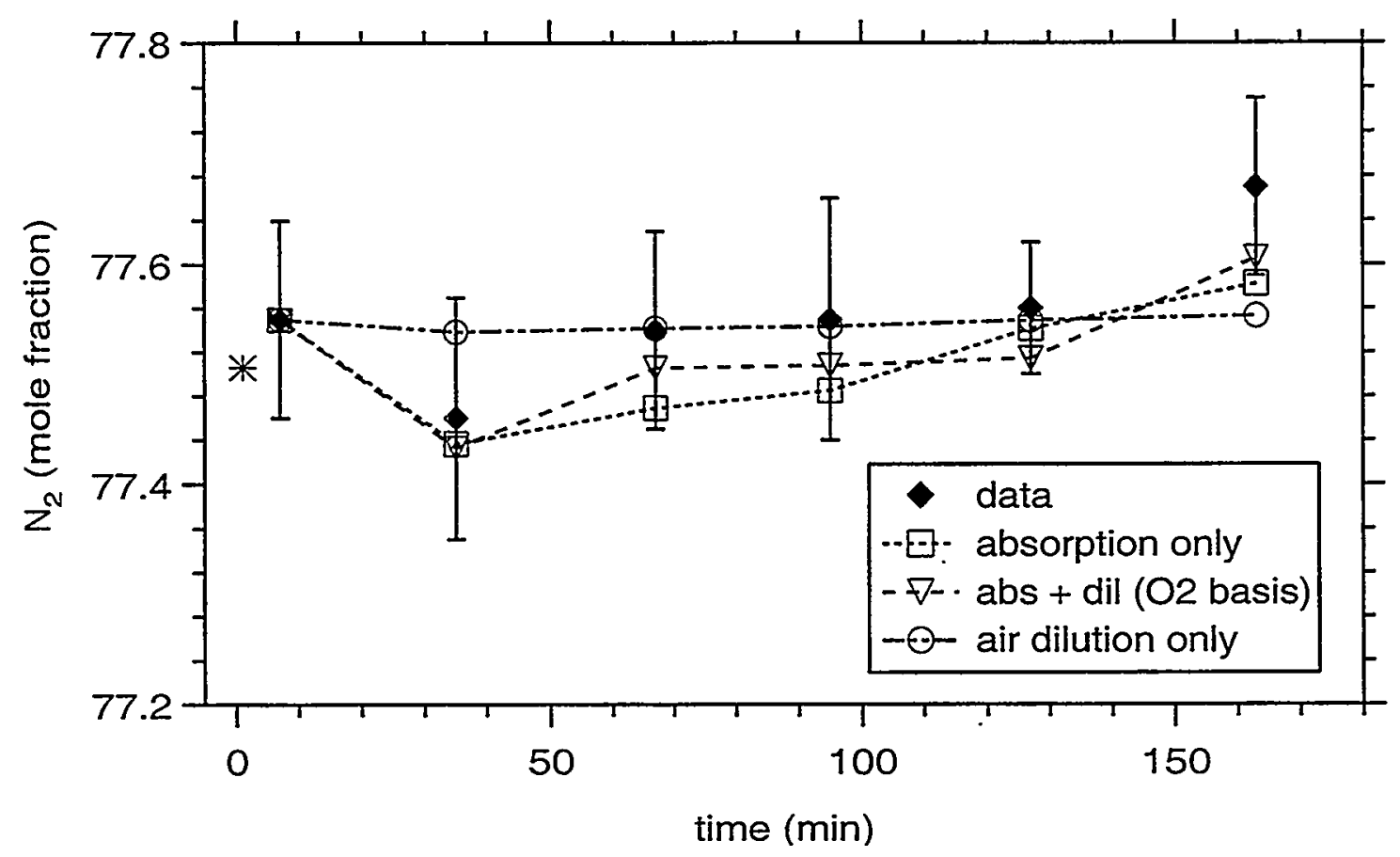

Figure 10. Measured and calculated temporal evolution of nitrogen in the test chamber during Dazzler. The calculations are initiated with the measured species concentrations at $\mathrm{t}=14$ minutes. The starburst indicates the calculated end-ofburn value.

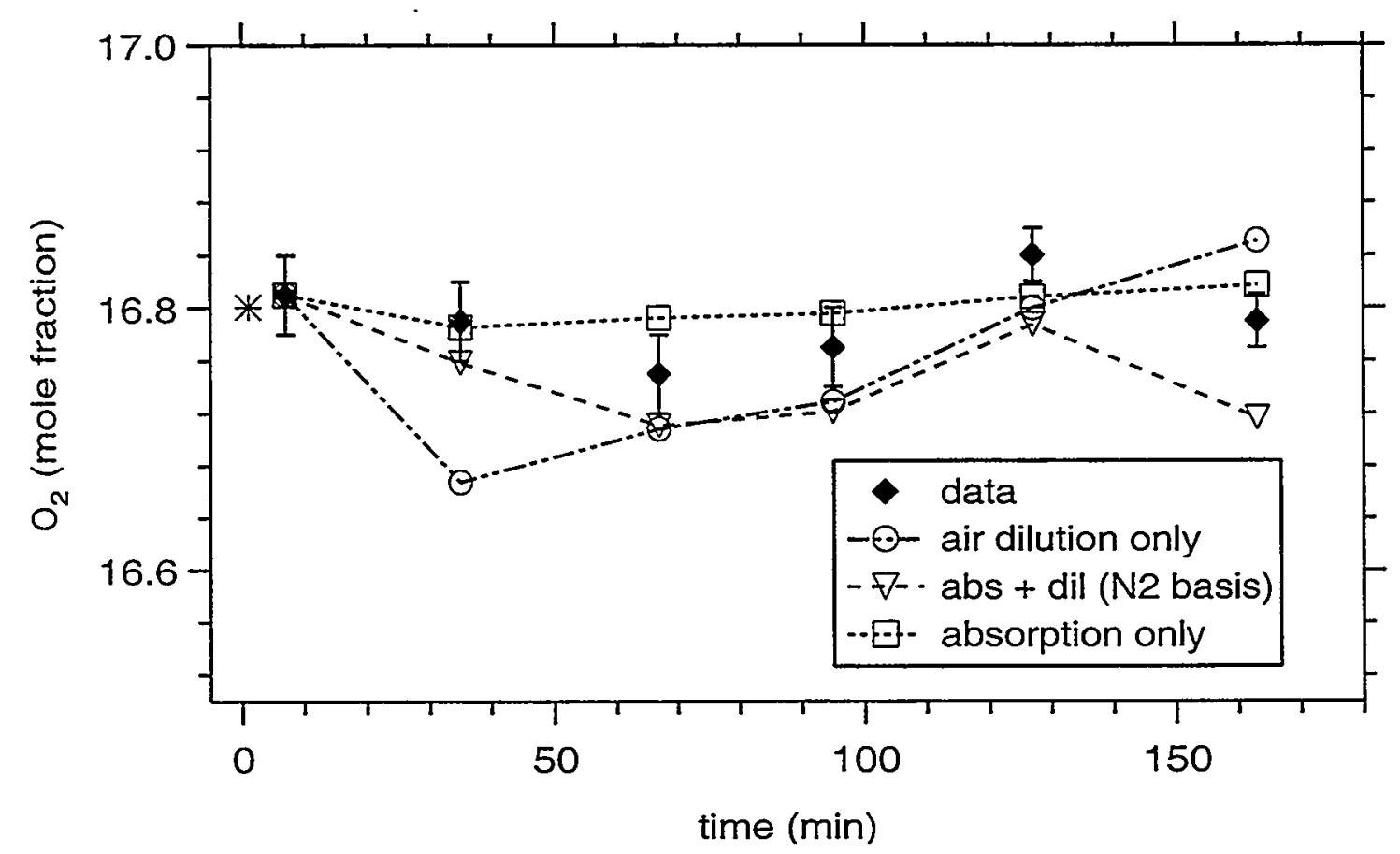

Figure 11. Measured and calculated temporal evolution of oxygen in the test chamber during Dazzler. The calculations are initiated with the measured species concentrations at $t=14$ minutes. The starburst indicates the calculated end-ofbum value. 


\section{Conclusions}

Analysis of the trends in the measured chamber concentrations during the JDT Program Phase II rocket motor burns in the NTS X-tunnel facility reveals that air infiltration occurred for two of the three tests and contaminated the measured gas concentrations at late sampling times. The analytical procedure described here also clearly reveals the effects of $\mathrm{CO}_{2}$ absorption into material surfaces on the temporal evolution of the measured species. For Thunderbird, the largest of the rocket motor burn tests and the one with the strongest evidence suggesting chamber leakage, air dilution was a very significant effect at later sampling times. In fact, our analysis indicates that air dilution effects at late time dominated $\mathrm{CO}_{2}$ absorption effects in this tests. For Sunspot, in which some evidence of chamber leakage was also present, the air dilution effects were much weaker and $\mathrm{CO}_{2}$ absorption was the dominant effect on the gas concentration temporal profiles. For Dazzler, no evidence of leakage was observed and consequently the chamber pressure remained above the local atmosphere for the duration of gas sampling. In this case, only small variations in the gas concentrations were evident over time and the analytical calculations reveal no significant effect of either $\mathrm{CO}_{2}$ absorption or air dilution.

Application of the analytical approach presented in this report leads to an improved understanding of the temporal trends in the gas concentration data and the $\mathrm{CO}_{2}$ absorption rates. Use of this analysis therefore allows for improvements in deducing the emissions from the rocket motor demil tests in the absence of $\mathrm{CO}_{2}$ absorption and air dilution effects. Calculation of the characteristic "end-of-burn" compositions based on this analysis show better agreement with expected, full-conversion compositions than earlier estimates.

\section{List of References}

"Department of Defense/Department of Energy Joint Demilitarization Technology Demonstration Program, Executive Summary of Phase I Demonstrations: Detonation of Conventional Weapons: 155-mm High-Explosive M107 Projectiles", Lawrence Livermore National Laboratory Report Number UCRL-ID-131252, July 1998.

"Department of Defense/Department of Energy Joint Demilitarization Technology Demonstration Program, Executive Summary of Phase II Demonstrations: The Low-Pressure Rocket Motor Burns in X-Tunnel", Sandia National Laboratories Report Number SAND20008202 , to appear.

Bellow, B. W., et al., (1998a), "Department of Defense/Department of Energy Joint Demilitarization Technology Demonstration Program: Executive Summary of Phase I Demonstrations", UCRL-ID-131252, July 1998.

Bellow, B. W., et al., (1998b), "Department of Defense/Department of Energy Joint Demilitarization Technology Demonstration Program: Executive Summary of Phase II Demonstrations", October 1998.

Velsko, C.A., and Watkins, B.E. (1999), "Gas Sampling and Analysis Results for LowPressure Burn Demilitarization of Rocket Motors", LLNL Internal Report, 1999. 


\section{UNLIMITED DISTRIBUTION:}

2 The Johns Hopkins University

Chemical Propulsion Information Agency

10630 Little Patuxent Parkway, Suite 202

Columbia, MD 2104-3200

Jim Cocchiaro

Tom Moore

1 US Environmental Protection Agency

Mail Drop 77B - ERC Annex

79 T. W. Alexander Dr

Research Triangle Park, NC 27711

William Mitchell

1 University of California

Los Alamos National Laboratory

P.O. Box 1663

Los Alamos, New Mexico

John Stephens, CST-1

2 University of California

Lawrence Livermore National Laboratory

P.O. Box 808

Livermore, CA 94550

Bruce Watkins, L 282

Carol Velsko, L 231

1 Bechtel Nevada

2621 Losee Road

North Las Vegas, NV $89030-4134$

Sam Williams

1 US Department of Energy/Nevada Operations Office

P.O. Box 98518

Las Vegas, NV 89193-8518

Deborah Howard

1 University of Nevada Las Vegas

Energy Research Center

P.O. Box 454027

Las Vegas, NV 89124-4027

Bob Boehm

3 US Army Defense Ammunition Center

$1 \mathrm{C}$ Tree Road

McAlester, OK 74501-9002

Jim Wheeler

Solim Kwak

Ed Ansell 
2 Radian International LLC

1093 Commerce Park Drive, Suite 100

Oak Ridge, TN 37830

John Carson

Walt Gray

$19001 \quad$ Mim John, 8000

$19054 \quad$ W.J. McLean, 8300

$19052 \quad$ Don Hardesty, 8361

$59052 \quad$ Chris Shaddix, 8361

$19052 \quad$ Sarah Allendorf, 8361

$19403 \quad$ Jim Wang, 8723

$19403 \quad$ Dave Ottesen, 8723

$19105 \quad$ Jane Ann Lamph, 8119

$59105 \quad$ Joel Lipkin, 8119

$39018 \quad$ Central Technical Files, 8940-2

$10899 \quad$ Technical Library, 4916

$19021 \quad$ Technical Communications Department 8815/Technical Library, MS 0899, 4916

$19021 \quad$ Technical Communications Department 8815 for DOE/OSTI 
This page intentionally left blank 